\title{
Abdução, inferência da melhor explicação e argumentos realistas: arguição ao artigo "a inferência abdutiva em Peirce" de Josiel Camargo
}

\section{Abduction, inference to the best explanation and realistic arguments: a rejoinder to Josiel Camargo's "the abductive inference in Peirce”}

\author{
GABRIEL CHIAROTTI SARDI ${ }^{1}$
}

\begin{abstract}
Resumo: Este breve artigo é uma arguição ao artigo "A inferência abdutiva em Peirce" de autoria de Josiel dos Santos Camargo publicado na Revista Diaphonía v. 7, n. 2, em 2021. Argumentarei que o autor cometeu um equívoco ao identificar o conceito de abdução com a inferência da melhor explicação e isso acarretou na incorreta identificação entre abdução e os argumentos realistas do milagre e da coincidência cósmica.
\end{abstract}

Palavras-chave: Abdução; Inferência da Melhor Explicação; Realismo Científico.

Abstract: This short paper is a rejoinder to "The abductive inference in Peirce" by Josiel dos Santos Camargo published in Diaphonía Journal v. 7, n. 2, in 2021. I will argue that the author made a mistake in identifying the concept of abduction with the inference to the best explanation and this resulted in the incorrect identification between abduction and the realist arguments of miracle and cosmic coincidence.

Keywords: Abduction; Inference to the Best Explanation; Scientific Realism.

Recentemente foi publicado na Revista Diaphonía (v. 7, n. 2, 2021) um profícuo artigo intitulado: "A inferência abdutiva em Peirce", de autoria de Josiel dos Santos Camargo. Neste texto, o autor apresenta de forma pontual a importância do raciocínio abdutivo na obra do filósofo Charles Sanders Peirce, seu desenvolvimento histórico, raízes e desdobramentos.

Todavia, embora Camargo tenha se prestado a realizar um excelente trabalho exegético evidenciando que o conceito de abdução sofreu diversas mudanças e desempenha um papel imprescindível no processo de geração de hipóteses científicas (e não no processo de avaliação delas), argumentarei, conforme se segue, que o autor incorreu em alguns equívocos - motivado por outros autores - ao abordar as influências contemporâneas do raciocínio abdutivo, a saber: identificar a abdução com a inferência da melhor explicação $(\mathrm{IBE})^{2}$ e com os argumentos realistas da coincidência cósmica e do milagre.

Como bem pontua Camargo a abdução de Peirce é uma forma de inferência lógica ampliativa diversa da dedução e indução que introduz novas hipóteses na ciência - as quais, posteriormente, deverão ser testadas sob o crivo da indução.

\footnotetext{
1 Doutorando em Filosofia pelo Programa de Pós-Graduação em Filosofia da Universidade de São Paulo (USP). É mestre e licenciado em Filosofia pela Universidade Estadual de Londrina (UEL). Realiza pesquisas na área de Filosofia da Ciência. E-mail: gabrielchi@hotmail.com

${ }^{2}$ Do original em inglês: Inference to the Best Explanation.
} 
Abdução, inferência da melhor explicação e argumentos realistas: arguição ao artigo "a inferência abdutiva em Peirce" de Josiel Camargo

[...] o papel fundamental de uma inferência abdutiva é seu papel ampliativo dentro de uma teoria explicativa de modo a possibilitar o progresso científico ao conceber novos conhecimentos fornecidos pela hipótese em questão, se acaso confirmada pela indução dentro da estrutura lógico-dedutiva das asserções (CAMARGO, 2021, p. 174).

É sabido que a abdução é um insight instintivo e criativo ou lampejo mental operado pelo cientista quando imerso no contexto do problema a fim de encontrar uma hipótese possível para explicar o fenômeno em questão (SANTAELLA, 2004, p. 103 - 104). Peirce deixa bem claro como se dá a dinâmica do raciocínio abdutivo na qualidade de um tipo de inferência que reúne ideias vagas e distintas em uma nova possibilidade hipotética:

Suponha que eu esteja há muito tempo intrigado com algum problema - digamos, como construir uma excelente máquina de escrever. Há várias ideias vagas em minha mente, nenhuma delas, tomadas isoladamente, possui qualquer analogia com meu problema principal. Mas algumas dessas ideias, presentes na consciência, porém ainda muito obscuras nas profundezas do pensamento subconsciente, conseguem se conectar de um modo particular de tal maneira que essa combinação apresente uma estreita analogia com a minha dificuldade. Quase instantaneamente essa combinação se destaca com vividez. Tal vividez não pode ser [o resultado de] uma contiguidade; pois se trata de uma ideia completamente nova. Ela jamais me ocorrera antes e, portanto, não está sujeita a nenhum hábito adquirido. Aparentemente, deve ser a sua analogia, ou semelhança formal, com o ponto crucial do meu problema aquilo que a faz emergir com vivacidade (PEIRCE, CP 7.498).

Dessa forma, a abdução não comportaria, na qualidade de um insight criativo, um processo avaliativo e seletivo de alternativas, visto que a hipótese sugerida pela abdução ainda se encontra no condicional de ser verdadeira, e esse condicional só é examinado posteriormente.

Esse é o primeiro ponto em questão aqui trabalhado, pois a inferência da melhor explicação, além de não ser a descrever um processo gerativo (aos modos como foi concebida originalmente por Gilbert Harman), é a descrição do processo seletivo e avaliativo entre alternativas rivais.

Ao inferir a melhor explicação se infere, do fato de que uma certa hipótese explicaria a evidência, a verdade desta hipótese. Em geral várias hipóteses podem explicar a evidência, por isso devemos ser capazes de rejeitar todas hipóteses alternativas antes de estarmos seguros ao fazer a inferência. Portanto se infere, da premissa de que uma dada hipótese forneceria uma "melhor" explicação para a evidência do que quaisquer outras hipóteses, a conclusão de que esta determinada hipótese é verdadeira (HARMAN, 2018, p. 326). 
É sabido, todavia, que a própria IBE sofreu modificações na literatura. A mais contundente e importante foi a reformulação apresentada por Peter Lipton em sua obra Inference to the Best Explanation (2004). Lipton, ao reformular o argumento de IBE, o converteu em uma estrutura de raciocínio que também narra os processos de geração e seleção de alternativas de forma conjunta, através dos dois filtros do seu novo modelo de IBE. Contudo, mesmo no modelo liptoniano de IBE há o processo seletivo envolvido, sobretudo quanto à análise das virtudes (ou considerações) explicativas da hipótese. Alexander Bird oferece uma síntese pontual das alterações de Lipton:

O modelo de Inferência da Melhor Explicação (IBE) de Peter Lipton tem as seguintes características: (a) IBE é um processo com dois estágios: (i) no primeiro filtro se extrai uma pequena lista de explicações potenciais de um fenômeno relevante; (ii) a partir desta pequena lista, no segundo filtro é escolhida a explicação preferida, a melhor explicação. (b) Em ambos estágios a escolha é orientada pelo entendimento explicativo [explanatory loveliness]. No estágio (ii), a melhor explicação, dentro das explicações potenciais, é a que proporciona maior entendimento [loveliest]. No estágio (i), a escolha da pequena lista é orientada pelas crenças de fundo, as quais foram selecionadas graças a IBE, ou seja, a partir [da busca] de entendimento explicativo. (c) As explicações em questão são contrastivas (BIRD, 2014, p. 375-376).

Mais uma vez está clara a distinção entre aquilo que Peirce chamou de raciocínio abdutivo e o que outros filósofos desenvolveram na qualidade de IBE, porquanto a abdução é a inferência de uma nova hipótese como um insight, e IBE é a descrição de um processo seletivo ou gerativo-seletivo sob avaliações de virtudes explicativas.

É importante ressaltar que o equívoco de Camargo não foi ingênuo ou fruto de má atenção do autor. Sua motivação reside em toda uma tradição na literatura de Filosofia da Ciência (a qual se origina com o próprio Harman) 3 que confundiu as formas de raciocínio. Porém, já se encontra disponível uma série de estudos que evidenciam que, embora muitos tenham chamado a abdução de IBE e vice-versa, isso é um erro motivado pela falta de atenção aos escritos e propósitos de Peirce acerca da abdução (MINNAMEIER, 2004; CAMPOS, 2011; PARK, 2017; AZAR, 2020; SILVA e SARDI, 2020).

Tendo clara essa diferenciação fundamental entre abdução e IBE, fica evidente, também, que a identificação entre abdução e os argumentos realistas do milagre e da

\footnotetext{
3 "“'A inferência da melhor explicação" corresponde aproximadamente ao que outros chamaram de "abdução", "o método das hipóteses", "inferência hipotética", "o método da eliminação", "indução eliminativa" e "inferência teórica". Eu prefiro minha própria terminologia porque acredito que ela evita a maior parte das sugestões enganadoras das terminologias alternativas" (HARMAN, 2018, p. 326).
} 
coincidência cósmica também estão equivocados, ao passo que Camargo identifica esses dois últimos como modelos de IBE (CAMARGO, 2021, p. 172 - 174).

É importante ressaltar que, embora tais argumentos possam ser lidos como aplicações de IBE, isso não significa, entretanto, que são a mesma coisa, pois se deve distinguir a proposta fundamental do argumento em si de uma possível aplicação sua.

Em suma, IBE é uma forma de raciocínio que foi pensada, em um primeiro momento, sem intenções realistas, mas somente como uma legitimação do processo inferencial dos cientistas (SILVA e MINIKOSKI, 2016, p. 238). Posteriormente os realistas científicos adotaram IBE por três razões principais: i) é um argumento eficaz para justificar a inferência de entidades inobserváveis na ciência; ii) é um retrato fidedigno da prática científica real; e iii) é uma forma de raciocínio que pode ser utilizada como um meta-argumento para o próprio realismo científico, isto é, afirmando que a postura filosófica do realismo é a que melhor se encaixa diante do sucesso da ciência em comparação à outras doutrinas (antirrealistas) (SILVA, 2011, p. 275).

Por fim, antes de mais nada, deve-se reconhecer que, embora existam esses pequenos equívocos (ao meu ver) no artigo de Camargo, seu trabalho não deve ser desconsiderado, ao passo que é uma análise histórica do conceito de abdução peirciana muito sólida e dialoga com uma tradição em filosofia da ciência que tem seu valor. Por mais que o autor identifique a abdução com outras estruturas argumentativas e alguns outros autores possam discordar, o artigo é uma excelente introdução no debate e Camargo pode possuir suas razões para insistir na identificação entre as estruturas de raciocínio - identificação essa da qual discordo.

\section{Referências}

AZAR, R. M. “¿Conduce la inferencia a la mejor explicación necesariamente al realismo científico?” In Revista Colombiana de Filosofía de la Ciencia, vol. 20, n. 40, 2020.

BIRD, A. "Inferência da Única Explicação". Tradução de Marcos Rodrigues da Silva. In Cognitio, vol. 15, n. 2, 2014.

CAMARGO, J. S. “A inferência abdutiva em Peirce”. In Diaphonía v. 7, n. 2, 2021.

CAMPOS, D. "On the distinction between Peirce's abduction and Lipton's Inference to the best explanation”. In Synthese, vol. 180, n. 3, 2011.

HARMAN, G. "Inferência da Melhor Explicação". Tradução de Marcos Rodrigues da Silva e Mirieli Sicote de Lima. In Dissertatio, v. 47, 2018.

LIPTON, P. Inference to the Best Explanation. London: Routledge, 2004.

MINNAMEIER, G. "Peirce-suit of truth: Why inference to the best explanation and abduction ought not to be confused". In Erkenntnis, vol. 6o, 2004.

PARK, W. Abduction in Context: The Conjectural Dynamics of Scientific Reasoning. Springer: 2017. 
PEIRCE, C. S. Collected Papers, (volumes 1 - 6, ed. by C. Hartshorne and P. Weiss; 7 - 8, ed. by A. Burks.) Cambridge, MA: Harvard University Press (Abreviado CP).

SANTAELLA, L. O método anticartesiano de C. S. Peirce. São Paulo: Editora UNESP, 2004.

SILVA, M. R. "O problema da aceitação de teorias e o argumento da inferência da melhor explicação". In Cognitio, v. 12, 2011.

SILVA, M. R.; MINIKOSKI, D. "Van Fraassen e a Inferência da Melhor Explicação”. In Problemata, vol. 7, n. 1, 2016.

SILVA, M. R.; SARDI, G. C. "A distinção entre abdução e inferência da melhor explicação: a abordagem de Daniel Campos". In Cognitio, vol. 21, n. 2, 2020.

Submissão: 18. 02. 2022

/ Aceite: 28. 02. 2022 